\title{
Vehicle-Level System Impact of Boundary Layer Ingestion for the NASA D8 Concept Aircraft
}

\author{
Ty V. Marien ${ }^{1}$ and Jason R. Welstead ${ }^{2}$ \\ NASA Langley Research Center, Hampton, VA, 23681 \\ Scott M. Jones ${ }^{3}$ \\ NASA Glenn Research Center, Cleveland, $\mathrm{OH}, 44135$
}

\begin{abstract}
The purpose of this study was to evaluate the vehicle-level impact of a boundary layer ingestion (BLI) propulsion system on a commercial transport aircraft concept. The NASA D8 (ND8) aircraft was chosen as the BLI concept aircraft to be studied. A power balance methodology developed by the Massachusetts Institute of Technology was adapted for use with the existing NASA sizing and performance tools to model the fuel consumption impact of BLI on the ND8. A key assumption for the BLI impact assessment was a $3.5 \%$ efficiency penalty associated with designing a fan for and operating in the distorted flow caused by BLI. The ND8 was compared to several other ND8-like aircraft that did not utilize BLI in order to determine the fuel consumption benefit attributable to BLI. Analytically "turning off" BLI on the ND8 without accounting for the physical requirements of redirecting the boundary layer or resizing the aircraft to meet the performance constraints resulted in a $2.8 \%$ increase in block fuel consumption to fly the design mission. When this non-physical aircraft was resized to meet the performance constraints, the block fuel consumption was $4.0 \%$ greater than the baseline ND8. The ND8 was also compared to an ND8-like aircraft with conventionally podded engines under the wing. This configuration had a 5.6\% increase in block fuel consumption compared to the baseline ND8. This result is more reflective of the real world impact if BLI is not an available technology for the ND8 design. The BLI benefit results presented for this study should not be applied to other aircraft that have a propulsion-airframe integration design or BLI implementation different from the ND8.
\end{abstract}

\section{Nomenclature}

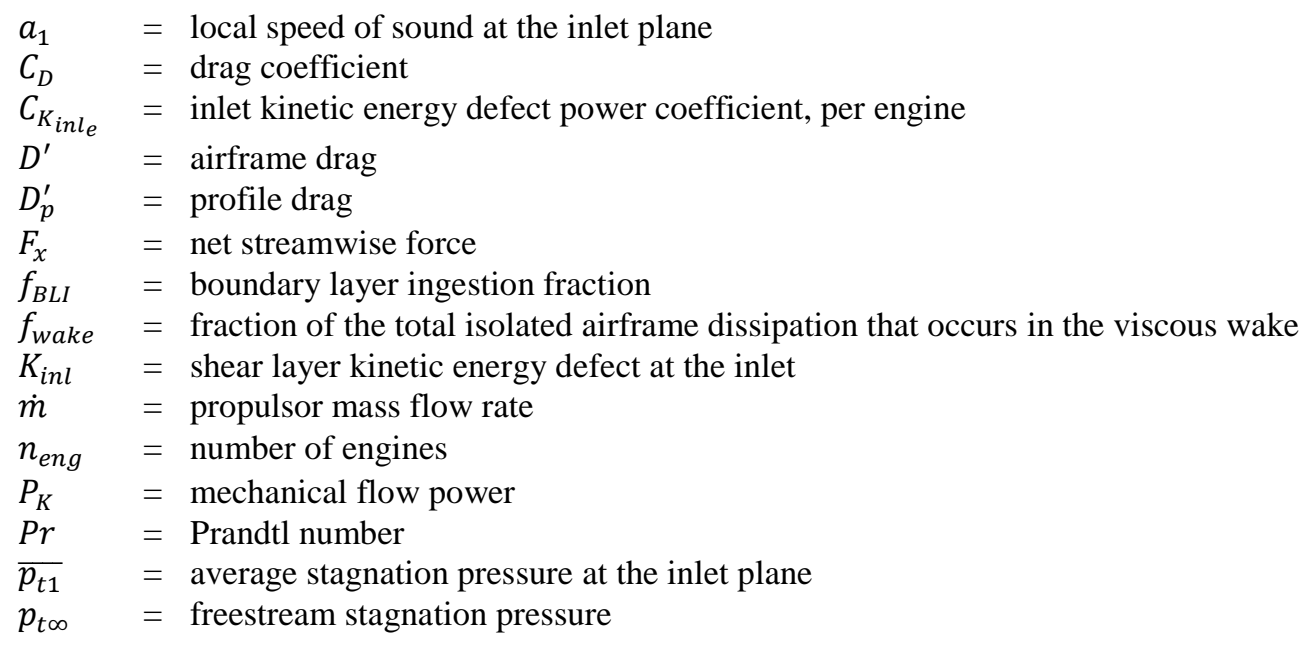

${ }^{1}$ Aerospace Engineer, Aeronautics Systems Analysis Branch, Mail Stop 442, Member AIAA.

${ }^{2}$ Aerospace Engineer, Aeronautics Systems Analysis Branch, Mail Stop 442, Member AIAA.

${ }^{3}$ Aerospace Engineer, Propulsion Systems Analysis Branch, Mail Stop 5-11, Member AIAA. 


$$
\begin{array}{ll}
V_{\text {jet }} & =\text { jet velocity } \\
V_{\infty} & =\text { freestream velocity } \\
\gamma & =\text { ratio of specific heats } \\
\Phi & =\text { dissipation rate }
\end{array}
$$

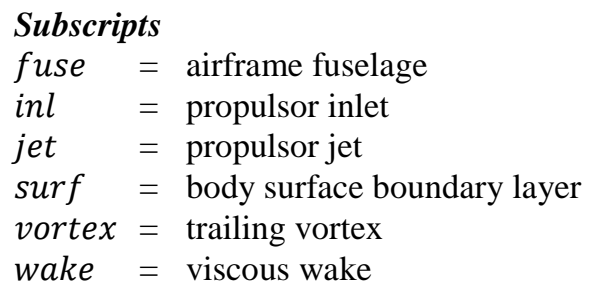

\section{Superscripts}

' $=$ non-BLI quantity

\section{Introduction}

$\mathrm{B}$ OUNDARY Layer Ingestion (BLI) is an airframe/propulsion technology receiving renewed interest in aircraft design circles due to the potential performance efficiencies it could deliver, assuming that the technical integration hurdles can be overcome. An integrated aircraft BLI system consists of a propulsor designed to capture and ingest a portion of the boundary layer (BL) air generated by the airframe. In most cases, the propulsor is embedded in the fuselage or wing. This propulsor must be designed to tolerate airflow distortions entering the inlet caused by the presence of the BL air.

There have been a number of recent transport aircraft design concepts that incorporate BLI in some manner in order to increase overall efficiency. One of those concepts is the Massachusetts Institute of Technology (MIT) D8 aircraft developed under a 2008 NASA Research Announcement (NRA) [1]. This aircraft concept, created by MIT, Aurora Flight Sciences, and Pratt and Whitney, featured three propulsors embedded in the aft fuselage that ingest the BL air from the top of the fuselage. The D8 design was later refined to employ two BLI propulsors instead of three [2]. In the 2010 NRA report, MIT claims a significant aeropropulsive benefit from BLI on the D8 configuration.

NASA's Advanced Air Transport Technology (AATT) Project has been researching BLI integration issues for the D8 and a number of other aircraft concepts. This previous research has verified that the application of BLI has demonstrable aeropropulsive benefits and the potential to reduce fuel burn, but the net system-level impact, when penalties such as lower fan efficiency are included, has not been fully explored. The AATT Project, therefore, desired an internal assessment of the vehicle-level system impact for BLI on a representative aircraft configuration using NASA tools and methods. The D8 was chosen as the platform to determine the vehicle-level BLI impact, as it is highly dependent on BLI for its performance and fits synergistically with previous AATT research. This study also provided an opportunity to incorporate knowledge obtained from the latest AATT BLI research into the analysis. No previous studies have leveraged the results of the recent wind tunnel experiments. In addition, this work allowed AATT researchers to better understand the vehicle design implications of an integrated BLI system and how to model that system with the existing NASA tool set.

\section{Problem Statement}

This study focused on the fuel consumption impact of the integrated BLI propulsion system that is part of the D8 aircraft design. There is no expectation that the BLI system performance for the D8 will be the same as the BLI performance for another aircraft configuration. There are many variables that affect the overall vehicle-level impact for a given BLI application, most significantly the amount of ingested BL air from the airframe. Additionally, this study makes no attempt to demonstrate the viability of the D8 configuration or to compare the performance of the D8 against any other existing configurations. The sole focus of this study is determining the fuel consumption impact of the BLI propulsion system.

The AATT Project has been involved in independently evaluating MIT's D8 concept for the past several years. In the course of studying and assessing the D8 concept, AATT researchers have developed their own analysis model, 
which has been designated the NASA D8 (ND8) (see Fig. 1). A separate designation was needed to differentiate the ND8 from the MIT D8 (or other D8 variants), since different assumptions and design and analysis tools were used to create the models. The ND8 model was used as the basis for the performance and sizing analysis in this study.

The BLI fuel consumption benefit was determined from a back-to-back comparison of BLI and non-BLI versions of the ND8. In the first set of comparisons, the baseline ND8 configuration was compared to a version of the ND8 with the BLI system analytically "turned off." This comparison allowed the impact of BLI on the ND8 configuration to be isolated from other integration and sizing effects. In the second set of comparisons, the ND8 was compared to several equivalent non-BLI ND8 designs, meaning ND8 derivatives that have the same airframe and engine technology levels but do not incorporate BLI into their design. These designs retain the major ND8 design elements (double-bubble fuselage, pi tail), and propulsion integration and sizing effects are included to account for the absence of BLI. These comparisons show the fuel consumption difference between the baseline ND8 and the "best" equivalent non-BLI design.

\section{Aircraft Model Development}

The ND8 is designed to carry 180 passengers, putting it in the same passenger class as a Boeing 737-800. The aircraft is designed to cruise at approximately $37,000 \mathrm{ft}$ at a cruise Mach number of 0.785 . The design range is 3,000 NM. The ND8 includes advanced technology assumptions for the aircraft materials, aerodynamics, and propulsion systems, representative of a 2035 entry-into-service date. The major design features of the ND8 aircraft are the BLI system, a "double-bubble" fuselage (provides additional lift and nose-up pitching moment, permits twin aisle seating), and a pi tail.

The ND8 was modeled using a ModelCenter [3] framework. This platform was used to connect the Flight Optimization System (FLOPS) [4] to the OpenVSP [5] geometry modeling tool and other custom sizing codes used to calculate component weights and wetted areas. FLOPS was used to estimate the aircraft aerodynamics and system weights, to calculate the mission performance, and to calculate the takeoff and landing performance. A custom engine cycle model was generated externally and provided to FLOPS via a tabular engine deck. The engine cycle parameters were not varied during individual sizing runs. A custom tail sizing algorithm was developed that used an empirical tail volume coefficient method [6] and considered engine-out conditions for the vertical tail sizing. The ModelCenter Design Explorer tool was used to minimize the mission block fuel for the given performance requirements and constraints by optimizing the wing area, engine thrust, and wing sweep.

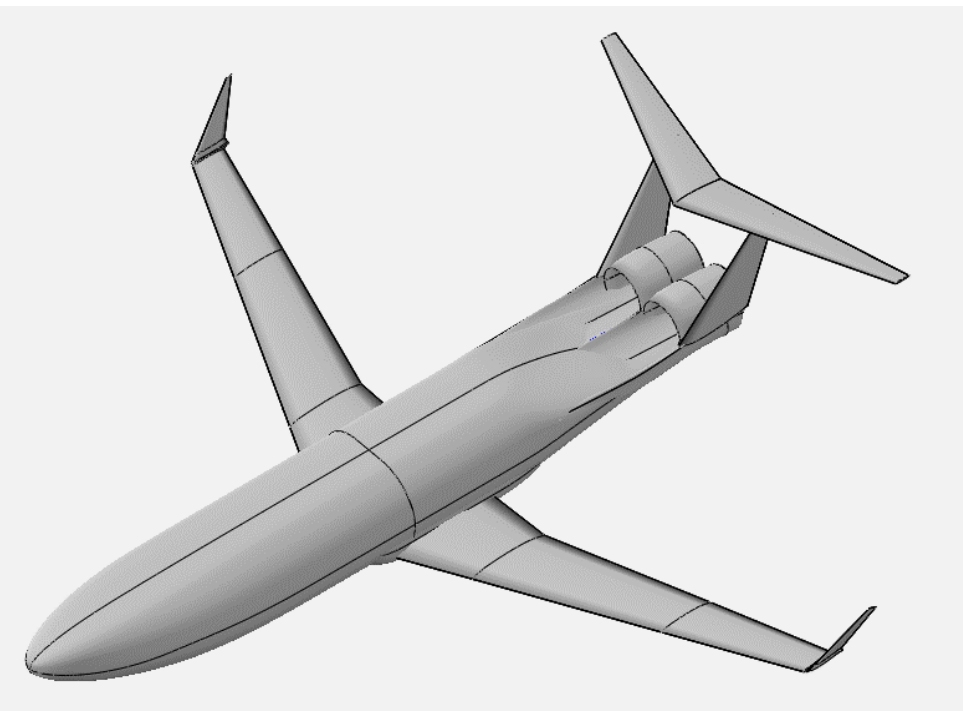

Fig. 1. NASA D8 Concept Aircraft. 


\section{A. Engine Model Development}

An engine model was developed for the ND8 aircraft at NASA Glenn Research Center. The model assumed a twospool, separate flow gas turbine engine. This high bypass ratio (BPR) engine model utilized a geared fan and a variable throat area fan nozzle. Materials and component efficiencies consistent with a 2035 entry-into-service were assumed. The model was developed using the Numerical Propulsion System Simulation (NPSS) [7]. The weights and dimensions for the engine were calculated using the Weight Analysis of Turbine Engines (WATE++) [8] program. NPSS and WATE++ were incorporated into a ModelCenter framework to enable the cycle design to be specified by the user, validated and run by NPSS, and the engine weights and dimensions automatically computed by WATE++.

The engine cycle design for the ND8 boundary-layer-ingesting turbofan is a slight deviation from the advanced technology reference engine described in Ref. [9]. Like the reference engine, the ND8 turbofan uses a gearbox on the low spool with a variable area bypass nozzle to maintain the fan operating line at peak efficiency. The ND8 propulsion system model has been adapted to fit with the ND8 vehicle design studies by replacing the normal engine inlet stagnation pressure recovery with a stagnation pressure loss defined by an inlet kinetic energy defect term, $K_{\text {inl }}$, which is a function of the ingested BL properties. This term allows calculation of the engine fan face stagnation properties for any given freestream condition and engine mass flow.

The ND8 engines have a technology level which is based on, and similar to, the advanced technology reference engine, but there are a few changes. The ND8 engines are designed to provide a target thrust at the max climb condition. Fan pressure ratio (FPR), with its large effect on specific thrust, may be varied to produce an acceptable engine diameter. Engine core size is also a concern for these advanced cycles; therefore, the engine OPR is adjusted based on the desired FPR and thrust levels to maintain the engine core size parameter at 3.0 pounds per second (pps).

\section{B. Aircraft Sizing Objectives, Variables, and Constraints}

For this study, the vehicle-level system benefit for BLI was defined to be the reduction in mission block fuel when comparing the baseline ND8 aircraft to a non-BLI version of the ND8. Therefore, the design objective for the aircraft sizing analysis was minimum block fuel for the design mission. The design variables used for aircraft sizing were: wing area, sea level static (SLS) engine thrust, and wing sweep.

The design constraints for the aircraft sizing were:

1) Range (3000 NM)

2) Excess fuel capacity (>than 0 )

3) Approach Speed (cannot exceed $150 \mathrm{kts})$

4) Takeoff Field Length $(<8000 \mathrm{ft})$

5) Landing Field Length $(<8000 \mathrm{ft})$

6) Second Segment Climb (excess thrust with one engine inoperative $>0$ )

7) Missed Approach Climb (excess thrust with one engine inoperative >0)

8) Instantaneous Rate of Climb at cruise condition (> $300 \mathrm{ft} / \mathrm{min}$ )

Also, the aircraft must be able to complete a reserve mission of $200 \mathrm{NM}$ to an alternate airport with 10 minutes of reserve hold time. An additional constraint was placed on the maximum engine diameter for the embedded engines. The engine fan diameter was constrained to 72 inches to allow the engines to fit between the ND8 vertical tails. This constraint was significant because it limited the minimum engine FPR and maximum BPR for the configuration.

\section{Power Balance Method for BLI Analysis}

There are a number of ways to conceptually view the benefit of BLI propulsion. The benefit can be viewed as a ram drag reduction due to lower velocity inflow at the propulsor inlet. The benefit can also be viewed as an airframe drag reduction due to the airframe wake being filled by the propulsive jet. Another way to view the BLI benefit is in terms of reduced dissipation from the airframe and propulsor far downstream. Although all of these perspectives describe the same physical phenomenon, some are easier than others to incorporate into an analysis model.

A thrust-drag bookkeeping method is the traditional way of determining the net thrust and drag for an aircraft configuration. For a traditional airframe and engine installation, this method is fairly straightforward. However, for an integrated BLI configuration, this method requires methodical bookkeeping of the airframe/engine components. In 
addition, an integrated airframe-propulsion analysis is needed for accurate results, as the presence of the engine affects the flow field and drag on the airframe and the inlet velocity profile changes with the engine operation point.

An alternative method for analyzing BLI aircraft configurations is the power balance method [10] conceived by Dr. Mark Drela of MIT. This method was used to determine the BLI performance in the design of the MIT D8 aircraft concept. Instead of focusing on thrust and drag, the power balance method compares the dissipation from the airframe and propulsor with the power input to the airstream by the propulsor. A significant advantage of the power balance method over traditional thrust-drag bookkeeping is that the airframe dissipation is largely unaffected by the presence or operation of the engine. Therefore, the airframe and propulsor can be analyzed separately. Dr. David Hall, et al., provide an aircraft performance analysis approach using the power balance method in their paper, "Boundary Layer Ingestion Propulsion Benefit for Transport Aircraft" [11]. In this paper, a mechanical power balance analysis is performed that characterizes the BLI benefit as the reduction in power input to the propulsor for a given thrust force. The power balance equation states that the power contribution of the propulsor balances the power consumed by the airframe plus the power delivered to the aircraft. A form of the power balance equation is given by Hall, et al.,

$$
P_{K}-\Phi_{j e t}=\Phi_{\text {surf }}+\Phi_{\text {wake }}+\Phi_{\text {vortex }}-F_{x} V_{\infty}
$$

The left-hand side of Eqn. (1) represents the net propulsive power. $P_{K}$ is the power added to the flow by the propulsor and $\Phi_{j e t}$ is the power lost to jet dissipation. The right-hand side of the equation represents the power consumed by the airframe. $\Phi_{\text {surf }}$ is the surface dissipation, $\Phi_{\text {wake }}$ is the wake mixing dissipation, $\Phi_{\text {vortex }}$ is the trailing vortex dissipation, $V_{\infty}$ is the freestream velocity, and $F_{x}$ is the resultant force delivered to the aircraft in the streamwise direction. For steady-state, level flight, $F_{x}$ goes to zero.

\section{Adaptation of Power Balance Method to Sizing and Analysis Tools}

The power balance method is a convenient way of modeling the BLI benefit on an aircraft because the details of what counts as thrust and what counts as drag are unimportant. The BLI benefit is expressed purely in terms of reduced power required from the propulsor. As convenient as this is on a conceptual level, it is not very useful when applied to traditional aircraft performance and sizing tools, such as FLOPS. FLOPS requires normal thrust and drag terms as inputs. A method was needed, therefore, to translate the power balance equation into a form with terms that are more compatible with FLOPS.

In their paper, Hall, et al., were able to do this by characterizing the airframe dissipation in terms of the isolated airframe drag. In other words, the airframe is considered in isolation without the BLI propulsion system. In addition, the propulsor performance is characterized in terms of the isolated airframe drag and engine nozzle exit conditions. Hall, et al., show that the propulsor mechanical flow power, $P_{K}$, is given by the equation:

$$
P_{K}=\frac{1}{2} \dot{m}\left(V_{j e t}^{2}-V_{\infty}^{2}\right)+K_{i n l}
$$

where $\dot{m}$ is the propulsor mass flow, $V_{j e t}$ is the jet velocity at the propulsor exit, $V_{\infty}$ is the freestream velocity and $K_{i n l}$ is the BL kinetic energy defect at the propulsor inlet. Hall, et al., show that $K_{i n l}$ is given by the equation:

$$
K_{\text {inl }}=f_{B L I}\left(1-f_{\text {wake }}\right) V_{\infty} D_{p}^{\prime}
$$

where the isolated airframe performance is denoted with a prime notation, ()$^{\prime}$. The parameter $f_{B L I}$ is the fraction of the total boundary layer that has been ingested, $f_{\text {wake }}$ is the fraction of the total isolated airframe dissipation that occurs in the wake, and $D_{p}^{\prime}$ is the profile drag of the isolated airframe. The parameter $f_{B L I}$ can also be defined as the ratio of $K_{\text {inl }}$ to the total airframe surface dissipation:

$$
f_{B L I} \equiv \frac{K_{i n l}}{\Phi_{\text {surf }}}
$$

In the case of the ND8, the propulsors are at the very back end of the fuselage, so we can assume that the surface dissipation of the BLI configuration, $\Phi_{\text {surf }}$, is approximately equal to the surface dissipation of the isolated airframe, $\Phi_{\text {surf }}^{\prime}$. The equation for $f_{\text {wake }}$ is given by: 


$$
f_{\text {wake }}=\frac{\Phi_{\text {wake }}^{\prime}}{\Phi_{\text {surf }}^{\prime}+\Phi_{\text {wake }}^{\prime}}
$$

where $\Phi_{\text {wake }}^{\prime}$ is the wake dissipation of the isolated airframe. Hall, et al., also characterized the airframe dissipation in terms of the isolated airframe performance:

$$
\begin{gathered}
\Phi_{\text {surf }}=V_{\infty} D_{p}^{\prime}-\Phi_{\text {wake }}^{\prime} \\
\Phi_{\text {vortex }}=V_{\infty} D_{i}^{\prime} \\
\Phi_{\text {wake }}=\left(1-f_{B L I}\right) \Phi_{\text {wake }}^{\prime}
\end{gathered}
$$

where $D_{i}^{\prime}$ is the induced drag of the isolated airframe. The jet dissipation is given by:

$$
\Phi_{j e t}=\frac{1}{2} \dot{m}\left(V_{j e t}-V_{\infty}\right)^{2}
$$

By substituting the dissipation terms (Eqns. (6)-(9)) and the $P_{K}$ term (Eqns. (2) and (3)) back into the power balance equation (Eqn. (1)), Hall, et al., directly relate the propulsor sizing to the isolated airframe drag and the BLI ingestion fraction:

$$
D^{\prime}-f_{B L I} D_{p}^{\prime}-F_{x}=\dot{m}\left(V_{j e t}-V_{\infty}\right)
$$

where $D^{\prime}$ is the total drag of the isolated airframe.

Almost all of the terms needed to characterize the ND8 airframe and engine performance in Eqns. (2), (3), and (10) can be determined at the cruise condition from available information. $D^{\prime}$ and $D_{p}^{\prime}$ are available from the FLOPS aerodynamic analysis. For a steady-state, level cruise condition, $F_{x}$ can be assumed to be zero. The parameters $f_{B L I}$ and $f_{\text {wake }}$ can either be estimated or calculated from a detailed aerodynamic analysis. The nozzle exit parameters $(\dot{m}$ and $V_{j e t}$ ) can be determined from the NPSS analysis, given the inlet conditions.

\section{E. Vehicle-Level BLI Assessment}

The adaptation of the power balance method to the aircraft sizing and performance tools enabled an assessment of the BLI system impact on the ND8 aircraft. There were five BLI effects considered for this vehicle-level analysis: reduced wake dissipation, increased propulsive efficiency, increased inlet stagnation pressure loss, reduced engine fan efficiency, and increased fan weight. These five effects are the ones considered most likely to directly affect the mission fuel consumption for the ND8. Fig. 2 shows these BLI effects and their representative positive or negative contributions at the vehicle level. The source of these BLI effects and how they were accounted for in the performance modeling is discussed below.

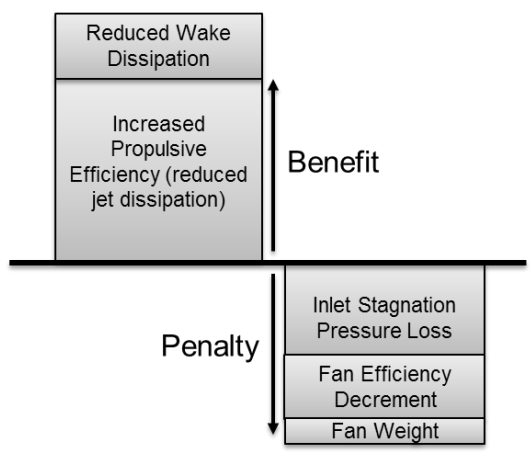

Fig. 2. Summary of BLI fuel consumption impacts. 


\section{BLI Benefits}

There are two primary fuel consumption benefits from BLI expected for the ND8: reduced wake dissipation and increased propulsive efficiency due to reduced jet dissipation. A BLI aircraft ingests and reaccelerates a portion of the airframe BL air. If this air is not ingested by the propulsor, it is part of the airframe wake and included in the wake dissipation term in the power balance, Eqn. (1). A smaller wake dissipation term means that the net propulsive power can be smaller to balance the equation. When the airframe BL air is ingested by the propulsor, the jet velocity exiting the propulsor is reduced. A reduction in jet velocity translates into a reduction in the jet dissipation. From the power balance equation, it is clear that a reduction in jet dissipation results in an increase in the net propulsive power.

Recalling Eqn. (10), the airframe performance (left-hand side) is balanced by the engine performance (right-hand side). Assuming steady-state, level flight $\left(F_{x}=0\right)$, the entire airframe benefit due to BLI is captured by the $f_{B L I} D_{p}^{\prime}$ term. This is effectively a drag reduction term that captures the reduction of the fuselage wake dissipation and the ingestion of the surface dissipation by the propulsor. Applying this term to the airframe performance side of Eqn. (10) allows for a reduction in the engine performance side $\left(\dot{m}, V_{j e t}\right.$, or some combination of the two). Reduction of these engine parameters leads to a smaller required mechanical flow power, $P_{K}$, determined in Eqn. (2). The parameter $f_{B L I}$ was calculated for the ND8 assuming that $40 \%$ of the fuselage BL is being ingested by the two engines at the cruise condition. This ingestion fraction assumption is supported by data from tests of the D8 conducted in NASA Langley Research Center's 14-by-22 ft wing tunnel [11]. The $f_{B L I} D_{p}^{\prime}$ term was modeled in FLOPS as an artificial reduction in fuselage wetted area.

An alternative way of viewing this benefit for the ND8 is to consider all of the fuselage "wetted" by the flow ingested into the engines to be part of the engine inlets. Effectively, that area is subtracted from the fuselage drag calculation and is added to the engine drag calculation.

\section{BLI Penalties}

There are three potential BLI fuel consumption penalties for the ND8 aircraft: inlet stagnation pressure loss, decreased fan efficiency, and increased fan weight.

The ingestion of fuselage BL air leads to a kinetic energy defect and stagnation pressure loss at the inlet. For example, at the engine design point $(\mathrm{M}=0.8,37,000 \mathrm{ft})$, the stagnation pressure loss associated with an ND8 engine ingesting $20 \%$ of the fuselage surface dissipation is about $2.7 \%$. NPSS requires the average inlet total pressure as an input to calculate the engine performance. The relationship between the BL kinetic energy defect and the average inlet stagnation pressure has been provided by Greitzer, et al. [12]:

$$
\overline{p_{t 1}}=p_{t \infty} \exp \left(-\frac{K_{i n l}}{\dot{m}_{\text {inl }}} \frac{\gamma \sqrt{P r}}{a_{1}^{2}}\right)
$$

where $\gamma$ is the ratio of specific heats, $\operatorname{Pr}$ is the Prandtl number, and $a_{1}$ is the local speed of sound at the inlet. All of the terms needed to calculate the average inlet total pressure at cruise are known except $K_{\text {inl }}$, which can be calculated using Eqn. (3). In order to calculate $K_{\text {inl }}$ for the ND8, only the isolated fuselage was considered, so Eqn. (3) becomes:

$$
K_{\text {inl }}=K_{\text {inl }_{\text {fuse }}}=f_{\text {BLIf fuse }}\left(1-f_{\text {wake }_{\text {fuse }}}\right) V_{\infty} D_{p_{\text {fuse }}^{\prime}}^{\prime}
$$

The BL ingestion fraction for the fuselage, $f_{B L I}$ fuse, was estimated to be 0.4 for the ND8 (20\% of the fuselage BL is ingested by each engine). This is consistent with the percentage of ingested BL assumed by MIT for the D8. The value of $f_{\text {wake }}$ fuse was estimated to be 0.1 for the ND8, based on an in-house analysis of the MIT D8 fuselage BL. The profile drag of the isolated fuselage, $D_{p_{f u s e}}^{\prime}$, was available from the FLOPS drag buildup for the ND8.

Since the value of $K_{i n l}$ is dependent on the flight conditions, this parameter was non-dimensionalized into a power coefficient by dividing by $1 / 2 \rho V_{\infty}^{3}$ and the number of engines, $n_{\text {eng }}$. This power coefficient, $C_{K_{\text {inl }}}$, simplifies to:

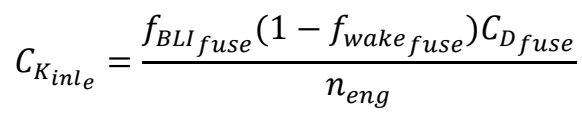


The coefficient of drag for the ND8 fuselage, $C_{D \text { fuse }}$, was estimated to be 0.00798 at cruise conditions by the FLOPS aerodynamic analysis. The number of engines, $n_{e n g}$, is two for the ND8. The value of $C_{K_{\text {inl }}}$ was calculated to be 0.0014364 at cruise, and this value was held constant for all flight conditions. This assumption simplified the analysis, but it does introduce some error in the engine performance calculations during the climb and descent segments. The NPSS analysis was modified to accept the $C_{K_{\text {inl }}}$ parameter, which allowed $\overline{p_{t 1}}$ to be calculated. The BLI penalty appears in the form of reduced engine performance due to the lower values of $\overline{p_{t 1}}$.

The second BLI penalty considered in this study is a decrease in engine fan efficiency when compared to a conventional podded engine installation. The ND8 engines experience distorted flow at the fan face due to ingesting the BL from the top of the fuselage. This inlet flow distortion presents a multitude of issues for the ND8 fans, including efficiency losses, reduced stability margin, aeroelastic issues, and reduced fan life due to high cycle fatigue. A completely new distortion-tolerant fan (DTF) design will be required for the ND8 engines. The ultimate impact of a DTF design on the engine fan efficiency for a BLI propulsor is an area that NASA's AATT Project has been researching for several years. A Boundary Layer Ingestion Inlet / Distortion-Tolerant Fan (BLI2DTF) Task was created to research BL ingestion technology that could enter service in the 2020-2025 time frame [13]. NASA partnered with United Technologies Research Center (UTRC) to design, analyze, and fabricate a BL ingesting inlet coupled with a 22" diameter distortion-tolerant fan, which was tested in the NASA Glenn Research Center 8'x6' Supersonic Wind Tunnel (SWT) [14]. The experiment was completed in December of 2016 and provided the data needed to validate the BLI2DTF propulsor performance. It is important to note that the BLI2DTF experiment used an inlet consistent with a hybrid wing body (HWB) aircraft design, which is significantly different than the ND8 inlet. However, learning from this test allowed researchers to estimate the fan efficiency penalty between a conventional fan operating in uniform flow and the ND8 DTF. This fan efficiency penalty was estimated to be $3.5 \%$.

The final BLI penalty considered in this study is an increase in the engine fan weight when compared to a conventional podded engine installation. The BLI inlet flow distortion introduces additional stresses and aeroelastic issues for the fan. The new DTF design for the ND8 could potentially lead to an increase in the fan weight as a result of the need to increase the fan blade stiffness. Learning from the BLI2DTF experiment has also provided insight for this issue. Discussions with engineers at UTRC have indicated that the fan weight penalty associated with a distortiontolerant fan should be negligible. Given this information, no fan weight penalty was assessed on the ND8 engines.

\section{Propulsion/Airframe Integration Benefits}

In addition to the BLI effects, the ND8 also benefits from the propulsion/airframe integration (PAI) design. The engines are embedded in the fuselage, which reduces the nacelle wetted area significantly compared to podded engines. Also, due to the PAI design, the nacelles are in a slightly reduced velocity flow compared to freestream, resulting in a small drag reduction. This was modeled as a decrease in nacelle wetted area beyond the actual area lost due to the embedded engines. Finally, the embedded engines place the thrust closer to the centerline of the aircraft, reducing the vertical tail size required to trim the aircraft during an engine-out condition.

\section{F. ND8 Analysis Cases}

The BLI impact analysis was performed by designing and modeling a baseline ND8 and a number of ND8-like aircraft at the conceptual level using the tools and methods previously described. The vehicle-level impact of BLI on the ND8 was determined by comparing the block fuel consumption of the baseline ND8 to the equivalent non-BLI designs. Comparisons were done between a baseline ND8 and ND8-like aircraft in order to focus solely on the BLI impact. Comparisons between the ND8 and a conventional baseline would also include the impact of the other ND8 technologies (e.g., "double-bubble" fuselage, pi tail). The ND8 analysis cases and related information are listed in Table 1.

This study began before the BLI fan efficiency penalty estimate based on the BLI2DTF wind tunnel test was available. Therefore, rather than make a guess at the penalty, the ND8 was initially modeled assuming no BLI fan efficiency penalty. This configuration was designated the "Initial" ND8 (Case 1) and used a polytropic fan efficiency of $95 \%$ for the embedded engines. The aero-propulsive BLI benefits were modeled as an artificial reduction in fuselage wetted area, and the inlet stagnation pressure loss penalty was applied to the engine model. The Case 1 aircraft was sized to meet all of the mission performance constraints while minimizing mission block fuel. A fan efficiency sensitivity study was performed with this configuration to determine how much block fuel increased when the polytropic fan efficiency decreased. Later in the study the BLI fan efficiency penalty estimate $(3.5 \%)$ became available. A fan efficiency of $91.5 \%(95 \%-3.5 \%)$ was assumed for the engine model of the "Final" ND8 (Case 2). The other BLI benefits and penalties were also applied to this configuration. The Case 2 configuration was sized for minimum block fuel while meeting the performance constraints. 
Two BLI-off configurations were created to determine the isolated effect of BLI on fuel consumption. These configurations had the BLI impacts turned off analytically in the FLOPS and NPSS models. The BLI-off configurations are considered non-physical aircraft because the BLI inlet stagnation pressure penalty is removed even though there is no physical device to prevent the BL air from entering the inlets. One of these BLI-off configurations (Case 3) was not resized to meet the performance constraints and was used to measure the impact of BLI with no sizing effects. The aircraft geometry, operational empty weight (OEW), and takeoff gross weight (TOGW) are identical to Case 2. However, the engine cycle characteristics are different from Case 2. The other BLI-off configuration (Case 4) was resized for minimum block fuel while meeting the performance constraints. Case 5 was a BLI-off configuration with an inlet BL diverter added. The diverter was modeled at a conceptual level -- weight and drag penalties were added to the FLOPS model but no detailed redesign of the aft fuselage was performed.

The final set of configurations were intended to determine the "best" ND8-like design (minimum mission block fuel) without BLI propulsion. Case 6 is an ND8 configuration with the engines moved to external pods attached to the aft fuselage. Since the engines are no longer located between the vertical tails, the aft fuselage can be slightly narrower. Also, the maximum fan diameter of the engines was no longer constrained to 72 inches. This resulted in higher BPR and lower FPR values for the engines. The fan polytropic efficiency was increased to $97 \%$ as a result of the lower engine FPR. Moving the engines shifted the center-of-gravity forward and the wing was moved forward about $3.5 \mathrm{ft}$ in order to maintain a similar static margin for pitch stability. This also slightly decreased the horizontal tail size. Moving the engines outboard caused the vertical tail size to increase due to the increased moment arm during an engine-out condition. Finally, changing the engine installation from embedded to podded significantly increased the nacelle wetted area. Case 7 is an ND8 configuration with the engines moved to external pods under the wing. Bending relief provided by the engines allowed the wing weight to decrease slightly. This configuration uses the same engines and aft fuselage geometry as Case 6. The wing is moved forward an additional $6.5 \mathrm{ft}$ (compared to Case 6) in order to maintain the pitch stability static margin. The landing gear length was increased to maintain the same tail strike angle. The tail sizes are also slightly different from Case 6 .

Table 1. ND8 Analysis Cases

\begin{tabular}{|c|c|c|c|c|c|c|}
\hline Case & Name & Description & BLI & $\begin{array}{c}\text { Sized to } \\
\text { meet } \\
\text { performance } \\
\text { constraints? }\end{array}$ & $\begin{array}{l}\text { Polytropic } \\
\text { Fan } \\
\text { Efficiency } \\
(\%)\end{array}$ & $\begin{array}{c}\text { Outer Mold Line } \\
\text { Representation }\end{array}$ \\
\hline 1 & "Initial" ND8 & $\begin{array}{l}\text { Base ND8 configuration with all BLI } \\
\text { benefits but no BLI fan efficiency } \\
\text { penalty applied. }\end{array}$ & Yes & Yes & 95 & \\
\hline 2 & "Final" ND8 & $\begin{array}{l}\text { Base ND8 configuration with all BLI } \\
\text { benefits and penalties applied. }\end{array}$ & Yes & Yes & 91.5 & \\
\hline 3 & $\begin{array}{c}\text { "BLI-off" } \\
\text { ND8, unsized }\end{array}$ & $\begin{array}{l}\text { Base ND8 configuration with no BLI } \\
\text { benefits or penalties applied. Same } \\
\text { TOGW as Case } 2 . \text { Does not meet all } \\
\text { the sizing constraints. }\end{array}$ & No & No & 95 & \\
\hline 4 & $\begin{array}{l}\text { "BLI-off" } \\
\text { ND8, sized }\end{array}$ & $\begin{array}{l}\text { Base ND8 configuration with no BLI } \\
\text { benefits or penalties applied. }\end{array}$ & No & Yes & 95 & \\
\hline 5 & $\begin{array}{l}\text { "BLI-off w/ } \\
\text { Inlet BL } \\
\text { Diverter" } \\
\text { ND8 }\end{array}$ & $\begin{array}{l}\text { Base ND8 configuration with weight } \\
\text { and drag penalties applied to account } \\
\text { for an inlet BL diverter. }\end{array}$ & No & Yes & 95 & \\
\hline 6 & $\begin{array}{c}\text { "Rear } \\
\text { Fuselage } \\
\text { Podded } \\
\text { Engine" ND8 }\end{array}$ & $\begin{array}{c}\text { Engines relocated to pods mounted to } \\
\text { the aft fuselage. Engines have higher } \\
\text { BPR, FPR, fan efficiencies than Cases } \\
\text { 1-5. Changes to wing location, tail } \\
\text { sizes. }\end{array}$ & No & Yes & 97 & \\
\hline 7 & $\begin{array}{l}\text { "Underwing } \\
\text { Podded } \\
\text { Engine" ND8 }\end{array}$ & $\begin{array}{l}\text { Engines relocated to pods mounted } \\
\text { under the wing. Engines have higher } \\
\text { BPR, FPR, fan efficiencies than Cases } \\
\text { 1-5. Changes to wing location, wing } \\
\text { weight, tail sizes, landing gear length. }\end{array}$ & No & Yes & 97 & \\
\hline
\end{tabular}




\section{Results}

\section{A. Fan Efficiency Sensitivity}

After the "Initial" ND8 (Case 1) was modeled and sized, a sensitivity study was performed on mission block fuel vs. engine fan efficiency. This was an important first step in the analysis since the magnitude of the engine fan efficiency penalty associated with BLI was not well understood at the time. The Case 1 polytropic fan efficiency and mission block fuel is shown in Fig. 3. The other points in the plot show the fuel needed to fly the design mission as the engine fan efficiency is varied from the Case 1 value. TOGW was held constant for all points on the plot and no aircraft resizing was done. (Fuel weight and cargo weight were traded in order to keep the TOGW constant.) The trend line shows that a $1 \%$ decrease in polytropic fan efficiency results in a $0.7 \%$ increase in mission block fuel weight. Since none of the aircraft were resized to meet the performance and sizing constraints, all of the points to the left of the Case 1 point will violate some of these constraints and are not considered feasible designs.

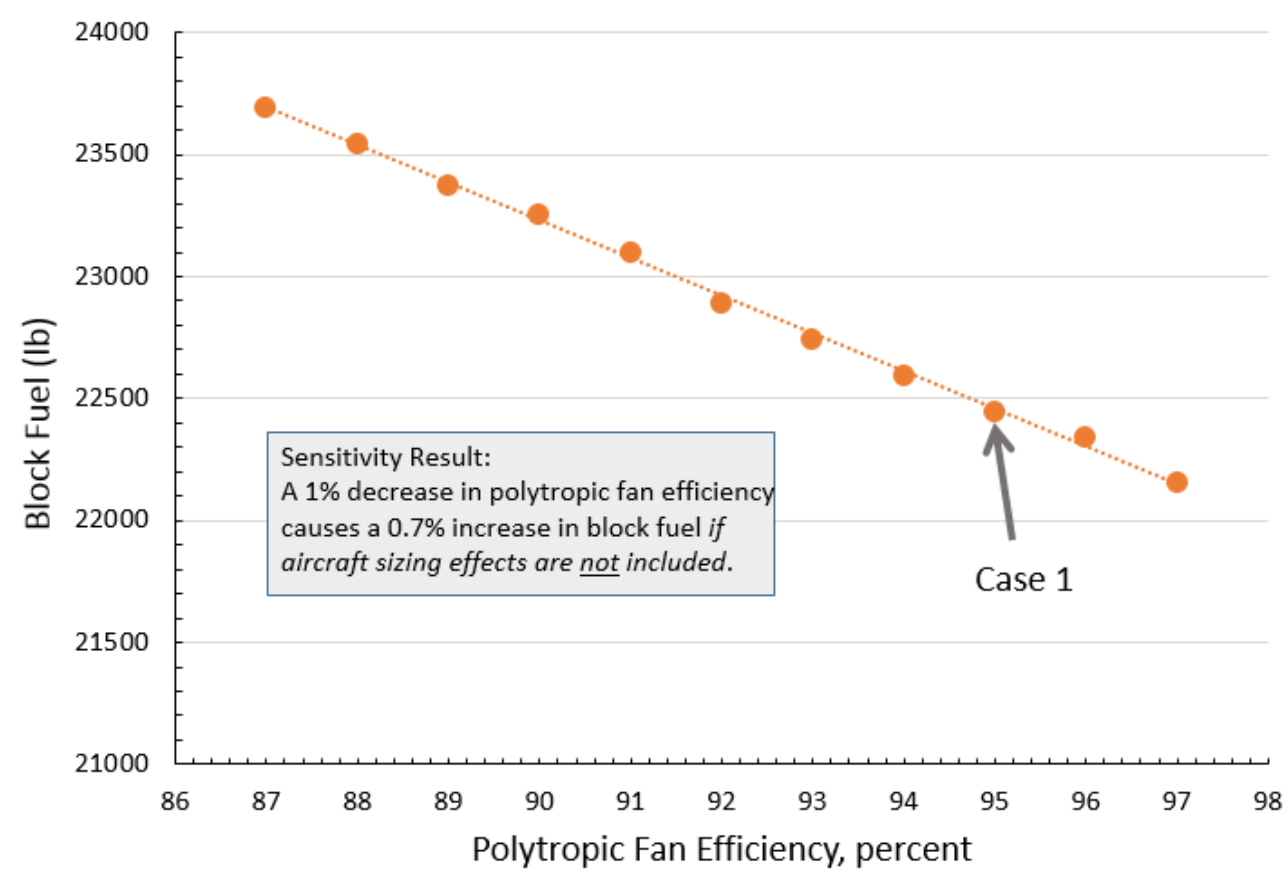

Fig. 3. ND8 engine fan efficiency sensitivity study.

\section{B. Isolated BLI Impact}

Case 2 is the ND8 configuration with all BLI benefits and penalties applied, including the BLI fan efficiency penalty. Case 2 is considered the baseline ND8 for this study. In order to determine the magnitude of the BLI impacts on the Case 2 configuration, each BLI benefit and penalty was individually turned off (analytically) in the model and the mission block fuel consumption for the design range was determined. Similar to the fan efficiency sensitivity study, the configuration was not resized after each benefit/penalty was turned off. The TOGW for each aircraft was held constant to match Case 2. The intent was to isolate the impacts of the BLI benefits/penalties from sizing effects.

A break-out of the BLI impacts on the Case 2 aircraft is shown in Fig. 4. When the BLI aeropropulsive benefit was analytically turned off, the block fuel consumption increased by $10.3 \%$. When the inlet stagnation pressure loss penalty was turned off for the engine model, the block fuel decreased by $4.9 \%$. Removal of the BLI fan efficiency penalty resulted in a $2.3 \%$ decrease in block fuel. Finally, when all of the BLI impacts were analytically turned off, the result was a $2.8 \%$ increase in block fuel. This configuration corresponds to Case 3 . As was previously mentioned, 
Case 3 is a non-physical configuration. In addition, the reduced performance of Case 3 means it no longer meets all of the performance constraints.

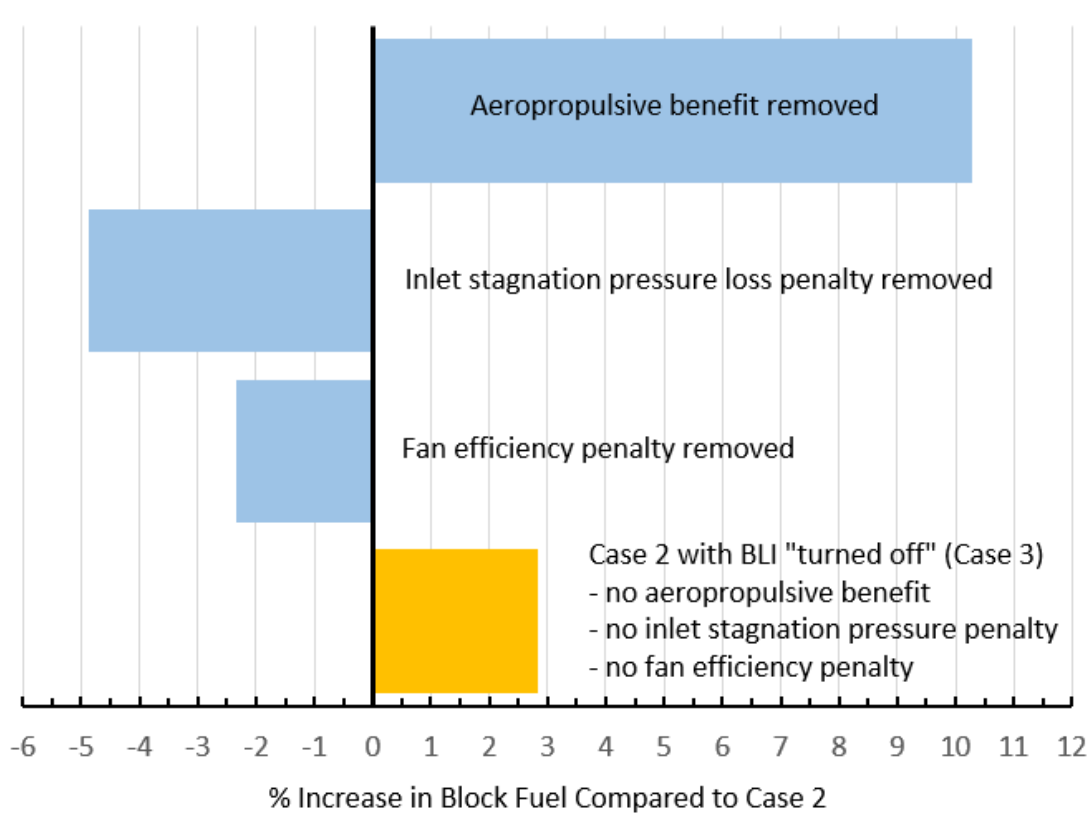

Fig. 4. BLI impact with the BLI effects analytically turned off one at a time.

\section{BLI Impact Including Sizing Effects and Configuration Changes}

After determining the isolated BLI fuel consumption impacts without any aircraft sizing effects, the next step was to include the sizing effects. The fan efficiency sensitivity study was repeated using Case 2 as the baseline configuration; this time each configuration was resized for minimum block fuel while meeting all the performance constraints. The results of this sensitivity study are shown in Fig. 5. The Case 2 block fuel is the baseline value and all other points on the plot are displayed as a percentage change relative to the Case 2 block fuel. The trend line shows that a $1 \%$ decrease in polytropic fan efficiency results in a $0.925 \%$ increase in block fuel if aircraft sizing effects are included. The Case 1 ("Initial" ND8) configuration is also shown on the trend line. Recall that Case 1 has no BLI fan efficiency penalty applied and represents the best possible outcome for a DTF design. When the 3.5\% BLI fan efficiency penalty is applied to that configuration, the resulting configuration (after resizing) is Case 2. Also shown in the figure is Case 4 ("BLI-off" ND8, sized). This configuration is the result of analytically turning off BLI for the ND8 and resizing the aircraft. The 4.0\% increase in block fuel compared to Case 2 represents the impact of the BLI effects. It does not include the propulsion integration changes needed to make a feasible non-BLI version of the ND8. These propulsion integration effects are captured in Case 7 ("Underwing Engine" ND8). This configuration represents the impact of removing BLI technology from the ND8 and redesigning the aircraft to have minimum fuel consumption. (The Case 7 configuration has lower fuel consumption than either Case 5 or Case 6, as will be seen later.) The 5.6\% difference in mission block fuel between Case 7 and Case 2 represents the total impact of BLI propulsion technology, including the BLI benefits and penalties as well as and propulsion integration effects. 


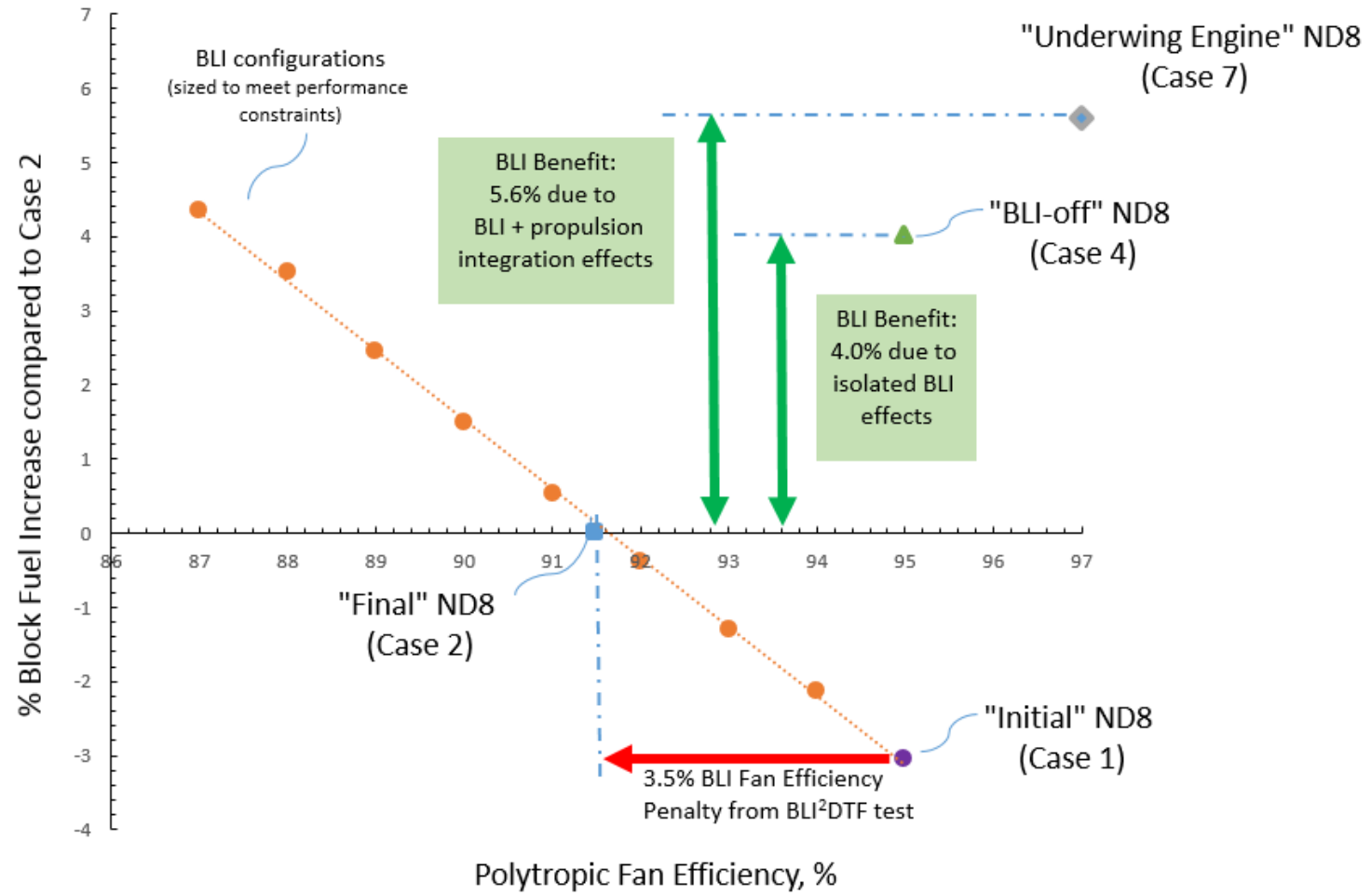

Fig. 5. BLI benefits with sizing effects included.

In order to obtain a deeper understanding of these results it is necessary to examine the cruise performance, wetted areas, and weights for the sized ND8 and ND8-like aircraft generated in this study. In the following discussion, the Case 2 characteristics are compared to the sized, non-BLI ND8 configurations (Cases 4, 5, 6, and 7). The order of these cases shows a general design evolution: the baseline ND8 (Case 2) was modified by analytically turning off BLI (Case 4), a BL inlet diverter was added for a more realistic drag calculation (Case 5), the engines were relocated to pods attached to the rear fuselage (Case 6), and the engine pods were then relocated under the wing (Case 7). The results for Case 1 and Case 3 are not included, as they are not relevant to this discussion. The trend lines in the following plots help to show the impact of the changes made between cases and are not intended to indicate a continuum of values between the cases.

The specific fuel consumption (SFC) and lift-to-drag ratio (L/D) at cruise are shown in Fig. 6 for the five cases. The SFC results show that Case 2 has the highest (worst) cruise SFC of all of the cases. This is a result of the bookkeeping methodology that was adopted for BLI configurations. The BLI penalties are bookkept on the engine side, which results in a reduction in thrust and fuel efficiency for the BLI engines. Moving from Case 2 to Case 4, BLI is analytically turned off and the engine SFC improves substantially. Comparing Case 4 and Case 5, there is very little change in the engine design, so there is no significant difference in the cruise SFC values. Cruise SFC improves significantly from Case 5 to Case 6 as the engines are moved to external pods on the rear fuselage. Maximum engine diameter is allowed to grow and engine efficiency increases as the BPR and FPR are allowed to reach more optimal values. There is no difference in cruise SFC between Cases 6 and 7 because the engine designs are identical for both cases.

In contrast with the SFC results, the baseline ND8 has the highest (best) cruise L/D. Again, this is due to the BLI bookkeeping methodology, which applies the BLI benefit as a drag reduction. Comparing Case 4 to Case 2, the cruise L/D drops by about $11 \%$ due to removing the BLI drag benefit and resizing the configuration. Predictably, cruise L/D drops further as a BL diverter is added (Case 5). Comparing Cases 5 and 6, the cruise L/D doesn't change appreciably as the engines are moved to pods and located on the rear fuselage. The increase in nacelle drag from the podded 
engines in Case 6 is approximately the same as the drag increment from removal the BL diverter in Case 5. Case 7 has a small advantage in cruise L/D compared to Case 6, mainly due to a slightly smaller tail.

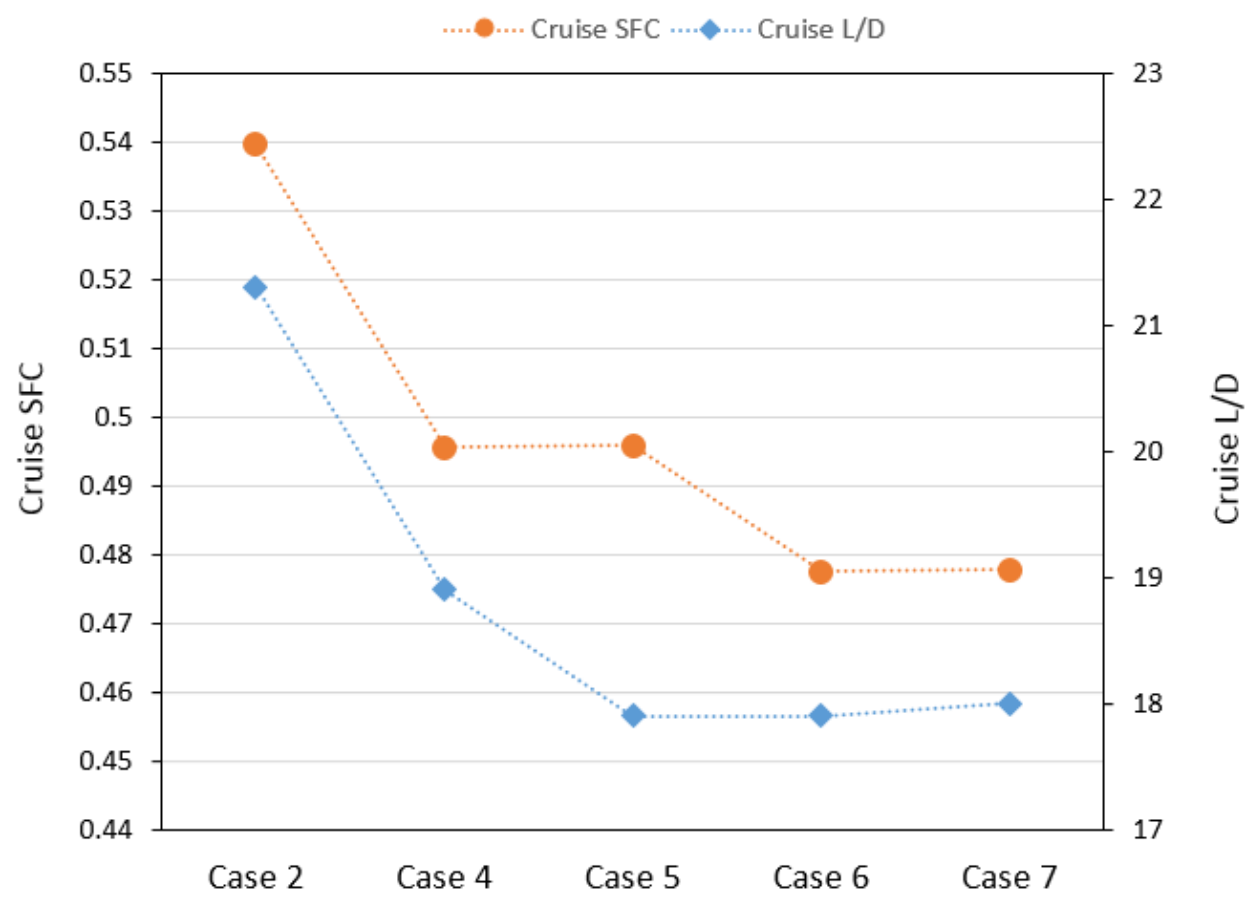

Fig. 6. Cruise performance comparisons.

The wetted areas for the various aircraft components (fuselage, wing, horizontal tail, vertical tails, and nacelle) are presented in Fig. 7. Moving from Case 2 to Case 4, the fuselage wetted area appears to increase significantly. As described previously, the BLI benefit is applied to the FLOPS model as an artificial reduction in the fuselage wetted area. When the BLI benefit is turned off, the original, true wetted area is restored. There are no other significant changes in wetted area between these cases. Comparing Cases 4 and 5, there are very small increases in the wing and nacelle wetted areas when the wing and engines are resized to account for the BL inlet diverter drag penalty, which is bookkept as an incremental drag penalty rather than an increase in fuselage wetted area. Moving from Case 5 to Case 6 , the fuselage wetted area decreases due to the narrowing of the aft fuselage, which no longer has the engines embedded between the vertical tails. The wetted area of the nacelles increases, as the Case 6 engines are fully podded. Also, the vertical tail wetted area increases because a larger tail is needed for the engine-out condition. Finally, the horizontal tail wetted area decreases slightly due to the change in center-of-gravity and wing position. Moving from Case 6 to Case 7, there are only very slight changes in wetted area. The largest change is a decrease in vertical tail wetted area. This result is slightly counter-intuitive - moving the engines under the wing from a fuselage-mounted arrangement should result in a larger moment arm in an engine-out condition and a larger vertical tail size. However, the lateral location of the podded engines is actually very similar in Case 6 and Case 7, due to the width of the doublebubble fuselage. In this case the driver is the center-of-gravity location for the Case 7 configuration, which is located further forward than Case 6 and allows for a smaller vertical tail size due to the larger moment arm. 


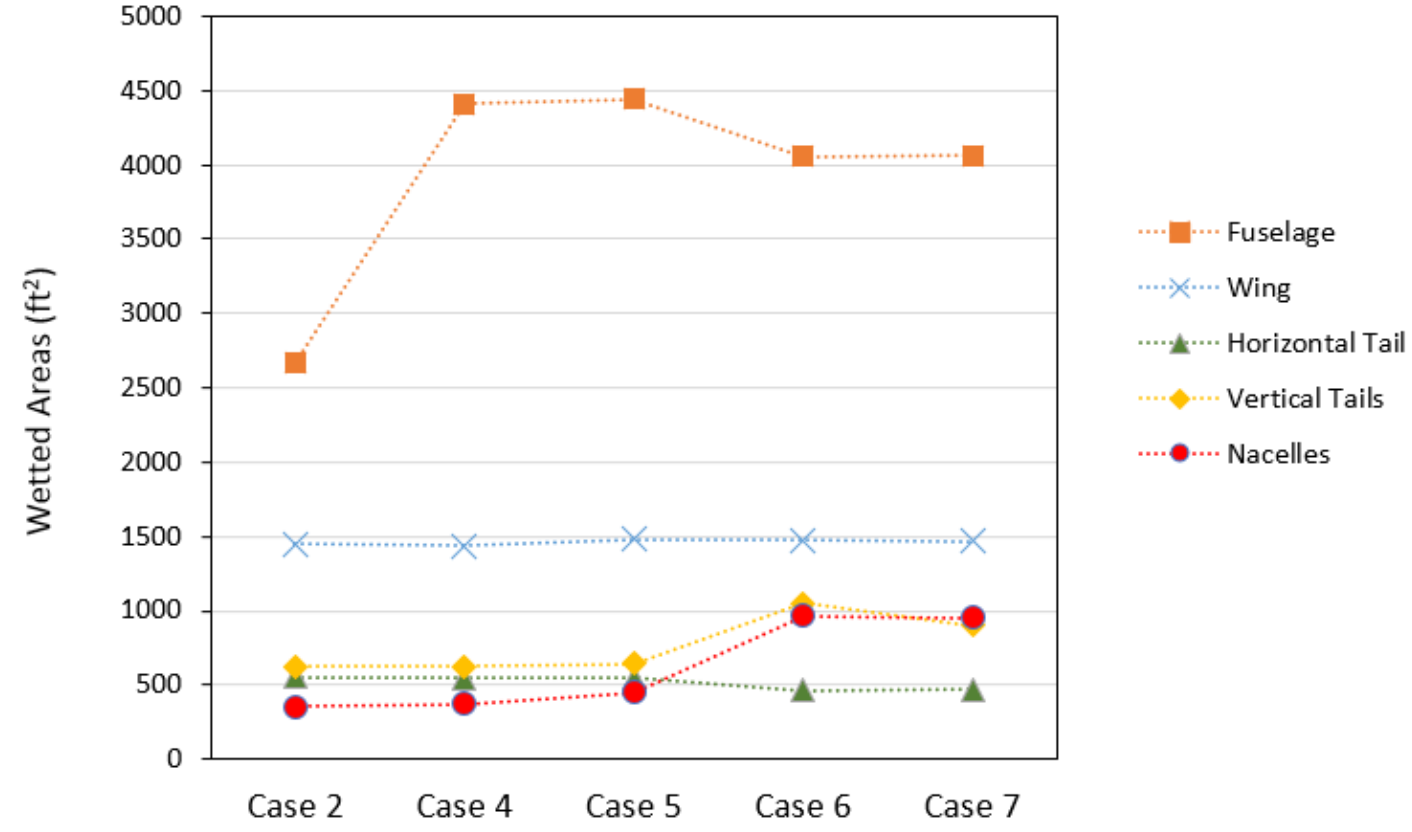

Fig. 7. Component wetted area comparisons.

Fig. 8 shows the mission block fuel and the takeoff gross weight (TOGW) for the different cases. The green arrows indicate the BLI benefit of the baseline ND8 (Case 2) compared to the non-BLI aircraft (Cases 4, 5, 6, and 7). Comparing Case 4 to Case 2, the block fuel increases by $4.0 \%$ due to turning off BLI. This result was seen earlier in Fig. 5. For Case 5, a drag and weight penalty is added to account for a BL inlet diverter and the block fuel consumption is $12.3 \%$ higher than Case 2. Moving from Case 5 to Case 6, the engines are relocated into pods attached to the rear fuselage and the block fuel decreases. Block fuel is still 7.6\% higher than Case 2. Referring back to Fig. 6, it is clear that the fuel burn advantage of Case 6 over Case 5 is a result of the engine performance gains, as L/D for both cases is virtually identical. Finally, moving from Case 6 to Case 7 the block fuel decreases slightly, but is still 5.6\% higher than the baseline. Case 7 is clearly the best non-BLI configuration in terms of fuel consumption (Case 4 is nonphysical). Compared to Case 2, the Case 7 configuration benefits from a better cruise SFC (no BLI fan efficiency or inlet total pressure penalties, larger maximum engine diameter). However, Case 2 has a significantly better L/D due to the aeropropulsive BLI benefit and smaller vertical tail and nacelle wetted areas than Case 7.

The TOGW values generally follow the same trend as the block fuel values in Fig. 8 . The changes in TOGW are composed of the fuel weight change and the change in empty weight due to configuration changes and resizing effects.

The airframe and engine characteristics for each of the cases (1-7) are presented in tabular form in the Appendix. 


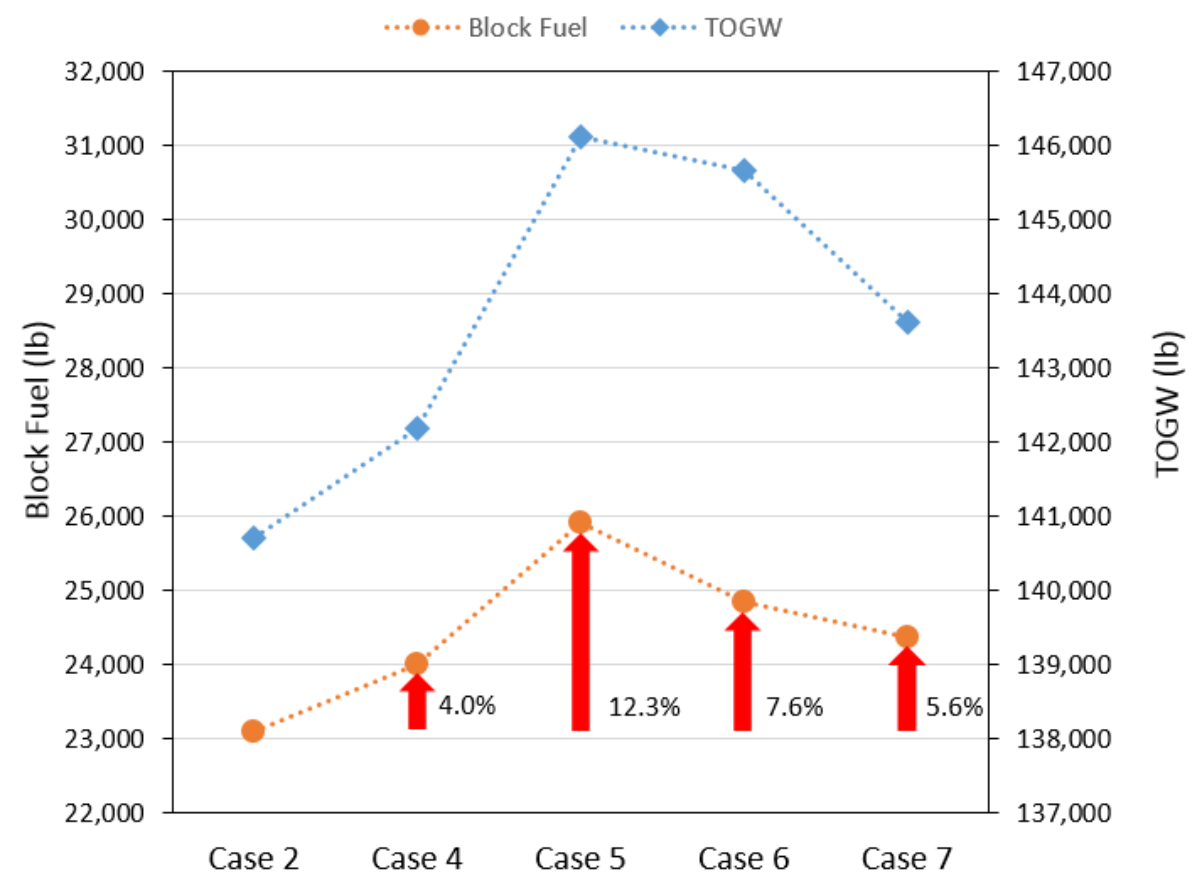

Fig. 8. Configuration weight comparisons.

\section{Conclusions}

A vehicle-level benefit analysis of the BLI propulsion system on the NASA D8 concept aircraft has been completed. The ND8 is a NASA design, using in-house conceptual design tools, based on the MIT/Aurora/Pratt \& Whitney D8 concept aircraft. The power balance methodology was used to model the BLI impact on the ND8. This methodology, developed at MIT, was adapted to use more traditional thrust/drag terms compatible with NASA performance analysis tools. Completion of this study fulfilled the original AATT Project objectives - to perform a vehicle-level assessment of BLI using the most recent knowledge from the BLI2DTF experiment, to better understand the vehicle-level design implications of BLI, and to adapt the NASA sizing and synthesis tools for a BLI application.

The BLI benefit was assessed in two ways. In the first set of comparisons, the isolated BLI benefit of the ND8 was estimated by analytically turning off the BLI impact in the performance model and comparing the mission fuel consumption to the baseline ND8. The mission block fuel increased by $2.8 \%$. However, this comparison did not include aircraft sizing effects for the "BLI-off" configuration. Resizing this configuration increased the TOGW and fuel consumption of the aircraft and resulted in a $4.0 \%$ fuel consumption increase compared to the ND8 baseline. Additionally, the "BLI-off" configuration was "non-physical" in the sense that there was no physical device to prevent the BL from being ingested into the engines. In the second set of comparisons, the baseline ND8 was compared to several non-BLI ND8 configurations. The intent was to compare the baseline ND8 to an ND8-like configuration that was not designed to incorporate BLI. All of the configurations were sized for minimum mission block fuel while meeting the performance constraints. The ND8 variant with underwing podded engines was determined to be the best non-BLI variant in terms of fuel consumption. This aircraft had 5.6\% higher block fuel consumption than the baseline ND8. This result is more reflective of the real world impact if BLI was not an available technology for the ND8 design. Even with a large fan efficiency decrement of $3.5 \%$ due to distortion, BLI propulsion still provides a significant reduction in fuel consumption compared to an equivalent technology non-BLI aircraft.

It is important to note that the BLI benefit values reported in this study are unique for the ND8 configuration and should not be interpreted as a generalized BLI benefit for other BLI aircraft designs or even other D8 configurations. There are a number of factors which determine this benefit, including the BLI ingestion fraction, the propulsion integration design, and the engine cycle design. Also, as is discussed by Hall, et. al.,[11] when comparing a BLI 
propulsor to a non-BLI propulsor, the BLI benefit may manifest as a lower power requirement for the BLI propulsor, a reduction in required mass flow (enabling a smaller, lighter BLI propulsor), or some combination of both. For a given aircraft, the BLI benefit will ultimately depend on multiple design trades involving the aerodynamic performance and the propulsion system weight.

\section{Appendix}

\section{A. Airframe Characteristics for Study Aircraft}

\begin{tabular}{|l|r|r|r|r|r|r|r|}
\hline \multicolumn{1}{|c|}{ Parameter } & Case 1 & Case 2 & Case 3 & Case 4 & Case 5 & Case 6 & \multicolumn{1}{c|}{ Case 7 } \\
\hline Wing Area $\left(\mathrm{ft}^{2}\right)$ & 1,132 & 1,143 & 1,143 & 1,129 & 1,173 & 1,185 & 1,176 \\
\hline SLS Thrust (lb) & 20,640 & 20,700 & 20,700 & 21,550 & 23,730 & 21,700 & 21,410 \\
\hline Wing Sweep (deg) & 25.8 & 25.1 & 25.1 & 25.7 & 25.0 & 23.3 & 24.2 \\
\hline Aspect Ratio & 12.8 & 12.2 & 12.2 & 12.4 & 11.9 & 11.8 & 11.9 \\
\hline Cruise L/D & 21.3 & 21.3 & 18.9 & 18.9 & 17.9 & 17.9 & 18.0 \\
\hline Cruise SFC & 0.527 & 0.540 & 0.495 & 0.496 & 0.496 & 0.478 & 0.478 \\
\hline OEW (lb) & 75,320 & 75,660 & 75,660 & 76,100 & 77,880 & 78,790 & 77,180 \\
\hline TOGW (lb) & 139,580 & 140,710 & 140,710 & 142,180 & 146,120 & 145,650 & 143,610 \\
\hline Block Fuel (lb) & 22,380 & 23,080 & 23,730 & 24,010 & 25,910 & 24,840 & 24,370 \\
\hline
\end{tabular}

\section{B. Engine Characteristics for Study Aircraft}

\begin{tabular}{|l|r|r|r|r|r|r|r|}
\hline \multicolumn{1}{|c|}{ Parameter } & Case 1 & \multicolumn{1}{c|}{ Case 2 } & Case 3 & Case 4 & Case 5 & Case 6 & Case 7 \\
\hline Polytropic Fan Efficiency & 0.95 & 0.915 & 0.95 & 0.95 & 0.95 & 0.97 & 0.97 \\
\hline Design FPR & 1.47 & 1.47 & 1.47 & 1.47 & 1.45 & 1.40 & 1.40 \\
\hline Max Climb BPR & 14.6 & 13.6 & 14.6 & 14.6 & 14.6 & 21.1 & 21.1 \\
\hline Max Climb OPR & 44.7 & 47.6 & 44.7 & 44.7 & 43.6 & 40.0 & 40.0 \\
\hline Turbine Inlet Temp $\left({ }^{\circ} \mathrm{R}\right)$ & 3,070 & 3,070 & 3,070 & 3,070 & 3,020 & 3,220 & 3,220 \\
\hline Engine Pod Weight (lb) & 5,640 & 5,720 & 5,640 & 5,640 & 5,490 & 6,450 & 6,450 \\
\hline Fan Diameter (in) & 71.9 & 71.4 & 71.9 & 71.9 & 71.3 & 81.8 & 81.8 \\
\hline
\end{tabular}

\section{Acknowledgements}

Thank you to those who contributed to this work: Mark Guynn and Jesse Quinlan of NASA Langley Research Center, Christopher Hartman of Analytical Mechanics Associates, Inc., Jeff Berton, Eric Hendricks, and Mike Tong of NASA Glenn Research Center. This study was supported by NASA's Advanced Air Transportation Technology Project. 


\section{References}

[1] Greitzer, E. M., Bonnefoy, P. A., de la Rosa Blanco, E., Dorbian, C. S., Drela, M., Hall, D. K., Hansman, R. J., Hileman, J. I., Liebeck, R. H., Lovegren, J., Mody, P., Pertuze, J. A., Sato, S., Spakovszky, Z. S., Tan, C. S., Hollman, J. S., Duda, J. E., Fitzgerald, N., Houghton, J., Kerrebrock, J. L., Kiwada, G. F., Kordonowy, D., Parrish, J. C., Tylko, J., Wen, E. A., and Lord, W. K., "N+3 Aircraft Concept Designs and Trade Studies, Volume 1," Final Report NASA/CR-2010-216794/VOL1, NASA Glenn Research Center, Cleveland, OH, 2010.

[2] Drela, M., "Development of the D8 Transport Configuration," AIAA-2011-3970, 29 ${ }^{\text {th }}$ AIAA Applied Aerodynamics Conference, Honolulu, HI, 27-30 June 2011.

[3] ModelCenter, Version 11.2, Phoenix Integration, Inc., Blacksburg, Virginia, 2017.

[4] McCullers, L. A., “Aircraft Configuration Optimization Including Optimized Flight Profiles,” Proceedings of the Symposium on Recent Experiences in Multidisciplinary Analysis and Optimization, NASA CP-2327, 1984.

[5] OpenVSP, Version 3.9.1, Open Source Software under NASA Open Source Agreement (NOSA) version 1.3, 2012.

[6] Morris, J. and Ashford, D. M., "Fuselage Configuration Studies," SAE Technical Paper 670370, 1967.

[7] Lytle, J. K., “The Numerical Propulsion System Simulation: An Overview,” NASA/TM-2000-209915.

[8] Tong, M. T., Naylor, B. A., “An Object-Oriented Computer Code for Aircraft Engine Weight Estimation,” NASA/TM 2009 - 215656, NASA Glenn Research Center, Cleveland, OH, 2009.

[9] Jones, S.M., Haller, W.J., and Tong, M.T., “An N+3 Technology Level Reference Propulsion System,” NASA/TM-2017219501, May 2017.

[10] Drela, M., "Power Balance in Aerodynamic Flows,” AIAA Journal, Vol. 47, No. 7, 2009, pp. 1761-1771.

[11] Hall, D. K., Huang, A. C., Uranga, A., Greitzer, E.M., Drela, M., Sato, S., "Boundary Layer Ingestion Propulsion Benefit for Transport Aircraft," Journal of Propulsion and Power, Vol. 33, No. 5 (2017), pp. 1118-1129.

[12] Greitzer, E. M., Bonnefoy, P. A., de la Rosa Blanco, E., Dorbian, C. S., Drela, M., Hall, D. K., Hansman, R. J., Hileman, J. I., Liebeck, R. H., Lovegren, J., Mody, P., Pertuze, J. A., Sato, S., Spakovszky, Z. S., Tan, C. S., Hollman, J. S., Duda, J. E., Fitzgerald, N., Houghton, J., Kerrebrock, J. L., Kiwada, G. F., Kordonowy, D., Parrish, J. C., Tylko, J., and Wen, E. A., "N+3 Aircraft Concept Designs and Trade Studies. Volume 2: Appendices-Design Methodologies for Aerodynamics, Structures, Weight, and Thermodynamic Cycles," NASA CR-2010216794/VOL2, December 2010.

[13] Arend, D. J., Tillman, T. G., and O’Brien, W. F., “Generation After Next Propulsor Research: Robust Design for Embedded Engine Systems," AIAA-2012-4041, 48 ${ }^{\text {th }}$ AIAA/ASME/ASEE Joint Propulsion Conference and Exhibit, Atlanta, Georgia, July 29-August 1, 2012.

[14] Arend, D. J., Wolter, J. D., Hirt, S., Provenza, A. J., Gazzaniga, J. A., Cousins, W. T., Hardin, L. W., Sharma, O. P., "Experimental Evaluation of an Embedded Boundary Layer Ingesting Propulsor for Highly Efficient Subsonic Cruise Aircraft," 53 ${ }^{\text {rd }}$ AIAA/SAE/ASEE Joint Propulsion Conference, Atlanta, GA, 10-12 July 2017. 